Novos e velhos desafios para as democracias em tempos de populismo

[New and old challenges for democracies in times of populism]

\section{Entrevista com Gianpietro} Mazzoleni

Interview with Gianpietro Mazzoleni

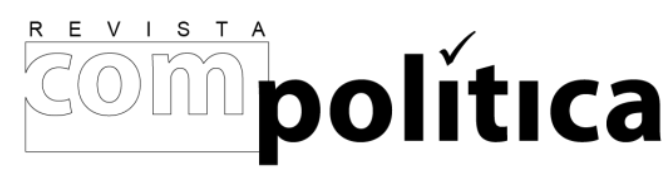

revista compolítica 2019, vol. 9(3)

compolitica.org/revista

ISSN: 2236-4781

DOI: 10.21878/compolitica.2019.9.3.376

(2) Open Access Journal

Liziane Guazina

Universidade de Brasília (UnB)

[University of Brasília] 


\section{Novos e velhos desafios para as democracias em tempos de populismo}

Liziane GUAZINA

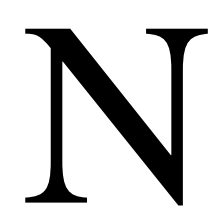

esta entrevista, Gianpietro Mazzoleni ${ }^{1}$, professor da Università Degli Studi di Milano e destacado pesquisador internacional na área de Comunicação e Política, discute a midiatização da política em tempos de mídias sociais digitais e analisa a relação entre a emergência do populismo no mundo e as novas estratégias de comunicação política nas redes. Além disso, comenta o processo de "memetização da política" (apropriação da agenda pública pelos memes), objeto de seu último livro, recentemente lançado na Itália (La Politica Pop Online, Mulino, 2019). A entrevista foi realizada por e-mail em outubro de 2019.

Desde o início dos anos 2000, você vem discutindo o papel das mídias sociais para a ascensão do fenômeno do populismo pelo mundo afora. No livro The media and neo-populism: a contemporary comparative analysis (2003), você analisa o modus operandi dos líderes políticos em diferentes sistemas midiáticos e democracias. $O$ que mudou daquele cenário para o atual?

A mudança mais evidente no campo da Comunicação é a difusão das redes sociais. A nova mídia social interativa tornou-se uma poderosa e adicional ferramenta para populistas aproximarem-se da população, difundirem suas mensagens e ganharem mais apoiadores. A grande mídia e a imprensa sensacionalista que analisamos no estudo comparativo foram, em certos casos, atores independentes no jogo de poder. Os populistas tinham ou que aceitá-las ou tentar subjuga-las. Muitas vezes, tiveram que flertar com a "lógica midiática", como quando ganham cobertura de mídia apenas por

\footnotetext{
1 Mazzoleni é o atual Presidente da Associazione Italiana di Comunicazione Politica (https://www.compol.it). Biografia e publicações em: www.gpmazzoleni.it
} 
usarem linguagem inflamada - algo que automaticamente atrai atenção midiática. Ainda, eles têm sucesso porque contam com proximidade ideológica de certos jornais ou canais de TV.

Essas estratégias ainda funcionam hoje em dia, mas populistas devem colocar uma enorme parcela de energia para manter as mídias sob vigilância, já que as mídias sociais se tornaram, com o tempo, mais atentas para não cair em armadilhas e, mesmo que não intencionalmente, contribuem para a visibilidade e popularidade dos líderes populistas. É por isso que a maioria dos líderes dependem fortemente do uso das mídias sociais, o que garante uma 'desintermediação', formando um contato direto com os públicos sem arriscar serem editados por jornalistas e comentaristas.

Na realidade, o que vemos atualmente em quase todos os países é uma comunicação populista 'híbrida', uma combinação de informação, desinformação, propaganda, mensagens furiosas, memes e etc. Para ser sucinto, a batalha para opinião pública é travada por vários atores - populistas e seus opositores, predominantemente no campo da comunicação.

Vários autores destacaram a recente emergência de líderes políticos da direita como Matteo Salvini, Jair Bolsonaro e Donald Trump, como parte de uma transformação mais significativa causada pelos avanços tecnológicos e pela popularização das plataformas digitais no dia a dia. Por outro lado, outros entendem o novo populismo como um sintoma da ruptura de democracias e como crises das de confiança nas instituições. Qual aspecto é mais importante para você? O novo populismo pode ser reconhecido como um sintoma ou causa da crise das democracias na Europa?

Sendo um acadêmico da área de Comunicação, eu posso ser levado a identificar, primariamente, nas transformações dos ecossistemas tecnológicos e midiáticos as causas para a explosão dos movimentos populistas ao redor do mundo. Contudo, eu concordo 
com os cientistas políticos que apontam para as tensões sociais e econômicas (e culturais) como ponto fulcral para a criação dos populismos de direita. A globalização, as mudanças no equilíbrio geopolítico de poder, as imigrações desreguladas e as crises econômicas colocaram pessoas, trabalhadores, cidadãos, partidos políticos e agências de assistência social sob stress sem precedente, aumentando os níveis de ansiedade social que forças políticas tradicionais parecem não conseguir resolver.

Isso criou um descontentamento político difuso no eleitorado de vários países, o que gerou um terreno fértil para populistas que são rápidos para converter a situação ao prometer solução fáceis para problemas que são realmente complexos. Pode também ser visto como um processo de 'ruptura de democracia' e, certeiramente, como uma queda na confiança do público em instituições democráticas tradicionais. Então, o surto de populismo na Europa e em outros lugares pode ser visto mais como um sintoma que como uma doença em si. Contudo, as variáveis da comunicação são fortemente conectadas à essas dinâmicas. Inclusive, até o ponto de perceber que, não o surgimento, mas a sorte dos líderes populistas e de suas crenças recaem, de forma profunda, no poder das mídias sociais.

Uma cobertura midiática tradicional de um populista não conhecido na era pré-Internet fez, certamente, ele/ela visível para um grande público. Porém, a partir daí, o líder tinha que lutar contra a instituição de mídia (prevalecendo pro-status quo) para conseguir propagar sua mensagem e isso nem sempre era uma batalha de sucesso. Muitos que querem ser líderes populistas tiveram que sair de cena. Hoje, as mídias sociais são indispensáveis para os líderes administrarem diretamente suas próprias estratégias de comunicação, para estabelecerem contato imediato com seus potenciais e atuais seguidores, contando com a extraordinária capacidade de compartilhar indefinidamente a mensagem por meio da enorme máquina de 'boca a boca digital'.

Não é por acaso que os mais presentes líderes populistas são personalidades especialistas nas mídias (sociais). É difícil imaginar o sucesso deles se eles não pudessem confiar nas tecnologias de comunicação. 
Em Mediatization and Political Populism (2014), você destacou como a nova mídia está se unindo à "antiga" mídia para radicalizar a midiatização da política. Além disso, você definiu, conceitualmente, que a mídia populista foi a 'engrenagem' para o populismo político, ao menos em sua pequena conceitualização do estilo dos atores políticos da comunicação política. Depois de mais de dez anos, nós ainda estamos vivendo a midiatização 2.0, como você discutiu no seu capítulo?

Como afirmado nas respostas anteriores, a nova mídia é essencial para entender a maioria dos desenvolvimentos políticos da última década. Contudo, o novo ecossistema, como defendido por Chadwick (2013), é de um tipo híbrido, combinando a ação ainda influente das mídias tradicionais com os recursos que ainda são amplamente pouco valorizados e estão disponíveis nas mídias sociais. Da mesma forma, o processo de midiatização antiga ainda está acontecendo, porque a lógica das mídias ainda está funcionando nas mídias comerciais, mas está aumentada pelas novas lógicas das mídias sociais digitais (Klinger \& Svensson, 2018). Política e políticos são afetados pelas novas tecnologias, mas, também, pelas práticas - que são cultural e socialmente formatadas.

As mudanças recentes no processo político italiano parecem depender de uma poderosa personalização digital da política. No caso do governo de Matteo Salvini, por exemplo, os seus perfis populares no Facebook e no Instagram foram focados em tornar públicas suas emoções, imagens pessoais e críticas a políticos de oposição. Similarmente, o presidente brasileiro Jair Bolsonaro tem usado 'Facebook lives' para situações muito particulares. Há pouco tempo, ele falou sobre as decisões governamentais, enquanto se recuperava de uma cirurgia no hospital. Essa instrumentalização da 
vida privada como um estilo de comunicação política pode ser entendida como uma forma de transformação da política em questão "pop" ou da moda?

A personalização digital da política é exatamente um efeito da Midiatização 2.0. O processo pelo qual as personalidades dos líderes tornam-se mais importantes que as dinâmicas institucionais, em que partidos são transformados em máquinas eleitorais a serviço dos líderes, é comumente conhecido na literatura acadêmica sobre midiatização. Isso é algo que é perfeitamente representado nas formas pós-ideológicas, pós-modernas, de dedicar-se à política e de fazer política, por todos os atores envolvidos: políticos, que investem fortemente na construção de suas imagens; da mídia, que prefere cobrir traços pessoais dos políticos do que suas ideias; e cidadãos, que parecem estar mais inclinados a seguir um líder que uma ideologia despersonificada. A era digital fez esses processos serem mais fáceis, rápidos e amplos.

No Brasil, memes estão tão presentes na cultura política pop online que já possuem um Museu Digital (http://www.museudememes.com.br), um projeto patrocinado pela Universidade Federal Fluminense. No seu livro La Politica Pop Online (Mulino, 2019), escrito com Roberta Bracciale, Professora da Universidade de Pisa, você discute o processo de "memizzazione" da política. Qual a característica principal desse processo? Pode o meme ser compreendido como uma maneira de participação política?

Nós discutimos no livro que o ecossistema de mídias digitais está tornando possível um processo que une a já conhecida midiatização da política, para transformar como a política é formatada no atual momento. Por 'memetização', nós nos referimos à apropriação de temas da agenda pública por atores sociais que misturam elementos da esfera política e da cultura moderna, presentes no sistema de comunicação híbrido. O resultado é uma 
aparente 'trivialização' dos temas políticos na agenda pública, que nós entendemos ser exatamente o impulso para torná-los acessíveis e entendíveis para grandes públicos.

Os memes, que são em sua maioria de estilo irônico e satírico apenas porque eles são objetos de prazer para a cultura moderna, servem como aliados valiosos para a participação na esfera pública e, consequentemente, são ferramentas extraordinárias para alavancar a democracia e o engajamento cívico.

Recentemente a democracia italiana foi chamada de 'La democrazia difficile: costantemente a rischio di fare una brutta fine per l'opera di forze illiberali. Di destra e di sinistra² (Angelo Panebianco, Corriere della Sera, 13/09/2019). No seu ponto de vista, qual é o papel da tradição midiática italiana no quebra-cabeças das forças políticas no país? Ainda, qual é a real dimensão da tradição midiática no sistema híbrido italiano atualmente?

Na Itália, há uma longa tradição de imprensa com inclinações. O 'modelo liberal' anglosaxão (Hallin \& Mancini, 2004) de imprensa independente não é típico da história das mídias do país. A maioria dos jornais (e, depois, dos canais de televisão) tem algum interesse extra para condicioná-los: de um lado a indústria e o setor financeiro criaram novas saídas para usar primeiramente como ferramenta política para influenciar e modelar as tomadas de decisão dos governos; do outro, todas as forças políticas coordenam suas próprias mídias, como mecanismos de modelar e cultivar opiniões e comportamentos de votos de seus seguidores.

O resultado foi e ainda é que a mídia tradicional 'escolhe lados', o que não ajuda a propiciar um debate democrático equilibrado e saudável. A explosão de sentimentos populistas, mesmo tendo sido abastecidos por certas saídas conservadoras, gerou, nos anos recentes, uma polarização de atitudes políticas mais tangível. Assim, um bom número de mídias conservadoras acaba protegendo líderes como Matteo Salvini. Do outro

\footnotetext{
${ }^{2}$ Em tradução livre: "A democracia difícil: constantemente em risco de ter um final ruim por obra de forças iliberais. De direita e de esquerda".
} 
lado, há o espectro político progressista com mídias libertárias motivando uma oposição diária.

Quem é o vencedor no campo de batalha é difícil de falar, porque antes da decisão de Salvini de sair da aliança com o Movimento Cinque Stelle ${ }^{3}$, o equilíbrio aparentava estar a seu favor. Com a formação da coalizão do novo governo entre o Movimento Cinque Stelle e o Partido Democrático de centro-esquerda, a barulhenta mídia de direita pareceu ter perdido sua conexão com a opinião pública italiana. É minha convicção pessoal que as instituições democráticas italianas (i.e. a Constituição de 1948) são suficientemente fortes para livrarem-se de tentativas de desestabilizar o país e de aberturas de caminhos para manobras autocráticas. Isso funcionou diversas vezes nas décadas o pós-guerra.

O uso massivo de todos os tipos de desinformação (incluindo fake news) como estratégia política foi uma característica da última eleição presidencial do Brasil em 2018. Na sua opinião, como garantir um justo e saudável debate político público no ambiente de pósverdade digital, caracterizado pela polarização política e ações baseadas em algoritmos?

Essa é uma pergunta em aberto, que desafia a democracia como a conhecemos até agora. Vários analistas já criaram diferentes respostas, mas é muito difícil encontrar uma solução que seja universalmente aceita. Aqueles que defendem novas e mais severas leis e regulamentações para restringir tentativas de criar e de disseminar desinformações, especialmente na internet, são contrariados pelos que defendem a liberdade total de expressão no espaço cibernético, abrindo espaço para o risco dos erros de informações.

Essas duas visões da natureza e do papel da web são, no atual momento, irreconciliáveis e eu não vejo uma medida institucional capaz de assegurar um fluxo confiável e

\footnotetext{
${ }^{3}$ O Movimento Cinque Stelle - M5S é um partido político italiano que atualmente faz parte da composição de governo. Fundado em 2009 pelo comediante Bepe Grillo, ficou conhecido por seu posicionamento antistabilshment e proposta de renovação na política. Muitos autores apontam que o M5S apresenta características populistas e, apesar de atuar legalmente como um partido, não se apresenta como tal em sua página oficial (www.movimento5stelle.it).
} 
equilibrado de informação. Há muitos atores envolvidos no campo e todos têm metas e agendas que correspondem, primeiramente, a restauração das forças políticas. Eu acredito que ao invés de acabar com os problemas dos erros de informação (que sempre foi uma característica da política - lembram-se da propaganda que inundou os anos da Guerra Fria?), nós devemos endereçar a questão de educar os cidadãos para lidarem com todas as informações de forma crítica. O que eu temo ser uma missão impossível.

\section{Como o campo de Comunicação Política pode contribuir para evoluir} o conhecimento sobre novas formas de participação política, populismo e autoritarismo difundidos pela Internet?

O subsídio para a Comunicação Política, especialmente no modelo comparativo, é essencial para qualquer entendimento profundo sobre processos de destacar tendências políticas, lideranças, normas e eventos singulares que preenchem as páginas da mídia doméstica e internacional. Pesquisa empírica sólida é uma obrigação para acadêmicos de Comunicação Política, porque ela provê as evidências cruciais que estão no único patamar em que podemos distinguir análises fortes de comentários de falsos conhecedores, que alegam interpretar a realidade apenas protegendo seus sentimentos pessoais. Isso requer que acadêmicos saiam de suas zonas de conforto e envolvam-se no campo, especialmente onde o autoritarismo, o populismo e a censura podem ser desafiados com as armas do discurso científico. É um trabalho árduo, estou consciente, mas não podemos apenas estudar desenvolvimentos políticos nos nossos laboratórios assépticos e arriscar, enquanto isso, sermos apagados pelo desarranjo das instituições democráticas

\section{Referências}

Chadwick, A. The Hybrid Media System: Politics and Power. Oxford University Press, 2013.

Hallin, D. e Mancini, P. Comparing Media Systems. Cambridge University Press, 2004.

Mazzoleni G. Mediatization and Political Populism. In: Esser F., Strömbäck J. (eds) Mediatization of Politics. Palgrave Macmillan, London, 2014.

Mazzoleni, G. e Bracciale, R. La Politica Pop Online, Mulino, 2019. 
Mazzoleni, G., Stewart, J. e Horsfield, B. (ed.) The media and neo-populism: a contemporary comparative analysis. Praeger Publishers, 2003.

Klinger, U. \& Svensson, J. The end of media logics? On algorithms and agency. New Media \& Society, Vol. 20(12) 4653-4670, 2018.

\section{A entrevistadora}

Professora de graduação e pós-graduação da Faculdade de Comunicação da UnB. Líder do Grupo de Pesquisa Cultura, Mídia e Política. Pesquisadora do Núcleo de Estudos sobre Mídia e Política (NEMP/UnB). E-mail: liziane.g@uol.com.br 